\title{
Validity of the Principle of Dynamic Equivalence
}

\author{
Yinhua Xiang \\ School of Foreign Languages, Chongqing Jiaotong University, Chongqing, China \\ Email: xiangyh6@163.com
}

\begin{abstract}
The principle of dynamic equivalence aims at arousing similar response between the source text readers and the target text readers. To achieve this goal, a D-E translation should strive for the "closest natural equivalent" of the source text. This approach toward translation is of great validity which is based on linguistic commonness of all langages and cultural and psychological similarities of all human beings. The former enables the possibility of faithful reproduction of the original message, namely, the "closest natural equivalent of the source- language message" while the latter guarantee the possibility of "similar response."
\end{abstract}

Index Terms — validity, principle of dynamic equivalence, linguistic bases, cultural and psychological bases

\section{INTRODUCTION}

Translation in essence is a kind of cross-linguistic, cross-cultural and cross-social communication. As a kind of communication, the basic requirement of translation is nothing but to establish equivalence between the source text and the target text. In other words, as the receiver of the source message and the sender of the target message, the translator should try his best to convey all the contents of the source text into the target text and arrange them in the way that the readers of the target text comprehend adequately the intent of the original author; otherwise, translation as a kind of communication would end in failure. However, as the basic requirement of translation, translation equivalence cannot be approached as a kind of absolute identity, but only as a kind of similarity or approximation. Such being the case, different types of translation equivalence may be established between the source text and the target text, and so far, different principles of translation equivalence have been put forward, such as lexical equivalence, syntactical equivalence, semantic equivalence and dynamic equivalence, etc. In a sense, some of these principles focus on formal equivalence, which can be described as "source-oriented", while others lay emphasis on equivalence of effect, which can be described as "receptor- oriented". The latter is represented by the principle of dynamic equivalence put forward by Eugene A. Nida, a dominant figure as a linguist and as a Bible translator among the modern translation theorists. The principle of dynamic equivalence aims at arousing "similar response" between the source text readers and the target text readers. To achieve this goal, a D-E translation should strive for the "closest natural equivalent" of the source text. Obviously, two basic requirements are involved here: on the one hand, the message of the source text must be faithfully reproduced; on the one other hand, the message must be so arranged in the target text as to have more or less the same effect on the target text readers as it did on the source text readers. This approach toward translation is of great validity and the present paper intends to discuss it from the following two aspects: 1. Linguistic bases, which enable the possibility of faithful reproduction of the original message, namely, the "closest natural equivalent of the sourcelanguage message." 2. Cultural and psychological bases, which guarantee the possibility of "similar response" between the source text readers and the target text readers.

\section{LINGUISTIC BASES}

Languages are different from each other, but they share many similarities, which make it possible to produce the "closest natural equivalent of the source -language message." This may be discussed as follows:

\section{A. Similarity of Kernel Sentences among All Languages}

It is known to all that Nida's theory is mainly based on the development of modern linguistics, especially on transformal-generative grammar. Seen in a generative perspective, all the sentences of a language consist of a surface structure and a deep structure. The "deep structure" refers to the basic abstract constructions from which all the sentences are generated by means of transformational rules. The basic abstract constructions determine the relationship of the fundamental elements of each sentence, thus determining the basic meaning. Each basic construction may be transformed into different kinds of surface presentations. For example, the simple sentence "Jesus rebuked Peter" has the following nine variations:

(1) Jesus rebuked Peter.

(2) Peter was rebuked by Jesus.

(3) Jesus' rebuking of Peter

(4) Peter's being rebuked by Jesus.

(5) the rebuke of Peter by Jesus

(6) Peter's rebuke by Jesus 
(7) the rebuking of Peter by Jesus

(8) It was Jesus who rebuked Peter.

(9) It was Peter who was rebuked by Jesus (Nida \& Taber, 1982) .

Inversely, a similar surface construction may involve different deep structures. For example, the phrases "his house", "his kindness", "his imprisonment" and "his failure" are made up of the same patterns of words: his + a noun. However, their basic relations are not the same, therefore the semantic relationships between "his" and the following nouns are different from each other, which can be described as follows:

His house: A possesses B

His kindness: $\mathrm{B}$ is the quality of $\mathrm{A}$

His imprisonment: A is the goal of B.

His failure: A performs B.

What is more important to translation is that the basic abstract constructions of different languages are very similar, though, not identical. Nida remarks:

In comparison with the theoretical possibilities for diversities of structures, languages show certain amazing similarities, including especially (1) remarkably similar kernel structures from which all other structures are developed by permutations, replacements, additions, and deletions, and (2) on their simplest structural levels a high degree of parallelism between formal classes of words (e.g., nouns, verbs, adjective, etc) and the basic function class in transforms: objects, events, abstracts, and relationals (Nida, 1964).

Since it is the basic construction that determines the meaning, and since all languages have more or less the same basic constructions, it is quite possible to reproduce the "closest natural equivalent" of the original text, and it is quite reasonable for Nida to put forward the approach of "back- transformation" which is just the reversion of Chomsky's transformation. He proposes:

Instead of attempting to set up transfers from one language to another by working out long series of equivalent structures which are presumably adequate to translate from one language into another, it is both scientifically and practically more efficient (1) to reduce the source text to its structurally simplest and most semantically evident kernels, (2) to transfer the meaning from source language to receptor language on a structurally simple level, and (3) to generate the stylistically and semantically equivalent expressions in the receptor language (Nida, 1964).

Translation is actually a language activity which, in a sense, involves a process of generating language (sentences); therefore the approach of back transformation is a reasonable and valid means to reduce the loss of meaning to the minimum in translation and at the same time makes the translation natural. As can be seen in the above quotation, the approach of back transformation involves the following three steps:

(1). The translator analyzes the source-language expression in terms of the basic kernel sentences and this enables him to have an adequate interpretation of the source text, which is the fundamental condition of transferring.

(2). The translator transfers the kernel forms of the source language to the equivalent forms of the receptor language, which helps to reduce the loss of message and makes it more likely to establish semantic equivalence between the source language and the target language.

(3). The kernel constructions of the receptor language are transformed into stylistically appropriate surface expression according to the transformation rules of the receptor language, so as to produce the closest natural equivalent. For example:

The motor was damaged by wrong power-line connection.

电动机被错误的电线连接损坏。

The Chinese version sounds quite awkward, for it is made just at the surface level. If we employ the approach of back-transformation, we can get a much better version.

First, by analyzing the original sentence, we get two kernel sentences:

(1) The power-line connection was wrong.

(2) (X) damaged the motor.

Besides, by analyzing, we know that (1) is the cause of (2).

Secondly, we transfer the two kernel sentences into similar Chinese kernel sentences.

(1) 电源连接是错误的。

(2) $(X)$ 损坏了电动机。

Thirdly, in accordance with the transformational rules of Chinese, we transform the two Chinese kernel sentences into the following surface presentation:

$\mathrm{B}$ : 电源接错, 致使电动机损坏。

As indicated in the above discussion, Chomsky's transformational grammar provides linguistic bases for the principle of dynamic equivalence. However, a few points deserve clearing up here.

As can be clearly seen, there are some differences between Chomsky's "deep structures" and Nida's "kernel sentences", for Chomsky's "deep structures" are at "a much deeper, more abstract (and less understood) level than Nida's kernels" (Gentzler, 1993, p.59). As a result some people argue against the principle of dynamic equivalence by saying that Nida has not interpreted Chomsky's theory adequately. Others argue against it by saying that Chomsky's theory itself, especially, his "deep structure" is not originally intended for translation. However, these oppositions are not 
reasonable. On the one hand, though translation theory itself is an independent subject, it certainly needs to make use of the development of other subjects, especially that of linguistics. On the other hand, since it is an independent subject itself, it should not become completely dependent on other subjects. Therefore, it is quite reasonable for Nida to make some adjustments when he adopted Chomsky's theory into his translation theory. Moreover, the fact that Chomsky's theory is not originally intended for translation does not necessarily mean that it is not applicable to translation. There are many instances that indicate that a theory aiming at one subject functions well in other ones.

\title{
B. Similarities of Languages on Surface Presentations
}

Besides the similarities on the level of the kernels, languages display some similarities on the surface presentations. For example, almost all languages have the subject-predicate structure and most languages share the same types of sentences, namely, declarative sentences, interrogative sentences, imperative sentences and exclamatory sentences. Similarities can be found even between languages of different families, like English, which belongs to Indo-European family, and Chinese, which belongs to Sino-Tibetan family. For example, they both share such sentence members as subject, predicate, object, adverbial and attribute. Furthermore, they are both SVO type of languages and possess the seven basic sentence patterns, that it, SV, SVO, SVOO, SVOA, SVC, SVA, SVOC. This indicates that most of the English sentence patterns can be potentially transferred into their corresponding sentence patterns in Chinese. For example:

(1) SV: He walks.

\author{
他散步。 \\ 他打篮球。 \\ 他给了我这本书。 \\ 他把它放在那里。 \\ 他是老师。
}

(2) SVO: He plays basketball.

(3) SVOO: He gave me this book.

(4) SVOA: He put it there.

(5) SVC: He is a teacher.

$\begin{array}{ll}\text { (6) SVA: He stands there. } & \text { 他站在那儿。 } \\ \text { (7) SVOC: He proved her wrong. } & \text { 他证明他错了。 }\end{array}$

Additionally, all languages are open systems in which new expressions are constantly being added to the lexical items to describe new ideas, inventions, etc., by means of borrowing from another language, inventing new expressions, or modifying the range of an expression of its own. All languages are basically the same in function, that is to say, "they can all express thoughts, reflect life, describe surrounding, portray images, create new words and produce literary works of various styles" (Liu Zhongde, 1991, p.107). Therefore, we can say that anything that is said in one language can be said in another.

The translation of the expression "white as snow", discussed by Nida, well illustrates this point. As he has noted, the translation of this expression for the readers who have no snow is possible, so long as "snow" as an object is not crucial to the message. Firstly, many people have a word for snow, even though they have not experienced it themselves, for they may have heard about the phenomenon. Secondly, in other instances, people do not know snow, but they do have "frost" and they speak about the two with the same term. Thirdly, many languages have quite equivalent idioms, such as "white as egret feathers" or "white as fungus", or they may use a nonmetaphor to express the concept "white as snow", such as "very white" (Nida \& Taber, 1982, p.4).

\section{Cultural AND Psychological BASES}

Translation is in fact a linguistic activity, but language and culture are inseparably intertwined. Thus, translation from one language to another actually involves going from one culture to another. Besides, Nida's principle of dynamic equivalence aims at producing similar response between source text readers and target text readers, which has much to do with people's mentality. So, discussing the validity of this principle cannot stop at linguistic level; it should also be discussed from the aspects of culture and mentality.

Generally speaking, similarities among human cultures and mentalities provide bases for achieving "similar response" between source text readers and target text readers.

Human beings, though living in different parts of the world, have a lot in common in culture and human experience is very much similar all over the world. For example, every one eats, sleeps, works; all men undergo the same life experiences such as birth, helplessness, illness, old age and death. Besides, all human beings are similar in the mental activities, for all the members of mankind have about the same biological equipment, or physiological structure. As an old Chinese saying goes, human beings, whatever their race or color, have at least seven emotions in common, that is, joy, anger, sorrow, fear, love, hate and desire. In short, all members of mankind share primal activities and thoughts, and the similarities between men are much more than the differences. Therefore, it is quite possible to arouse similar response between source text readers and target text readers.

Nida makes a more penetrating analysis of this issue from the following aspects:

(1) All peoples share essentially the same fundamental mental process no matter what race or culture they belong to. Besides, even some tendencies to generalization appear to be very similar between peoples of widely different cultural background.

(2) There is a high degree of similarity of somatic reactions among peoples all over the world. Certain automatic 
responses are universal. For example, people of all cultures may blush and their blood pressure becomes higher when they are in anger. Of course, the causes for somatic reactions may sometimes differ from culture to culture, but the form of the somatic response is remarkably similar, which provides a basis for producing similar response between the two groups of readers.

(3) Of the major elements of culture, namely, material, social, religious, linguistic, and esthetic, all societies participate in all phases and in rather analogous ways. Though specific behavior within any one area of life may differ, the range of common human experience is sufficiently similar which provides a basis for mutual understanding.

(4) People all possess capacity for adjustment to the behavioral patterns of others. They not only have capacity of recognizing other "tokens" of behavior, but are also able to adjust to such tokens as an organized system. It seems people in the world have a kind of grid, which they can use to reinterpret experience in terms of some other conceptual framework so long as there is a measure of willingness to do so, and a degree of good will inherent in the activity (Nida, 1964).

Through the above analysis and illustration, Nida draws the following conclusion:

Despite the fact that absolute communication is impossible between persons, whether within the same speech community or in different communities, a high degree of effective communication is possible among all peoples because of the similarity of mental processes, somatic responses, range of cultural experience, and capacity for adjustment to behavior patterns of others (Nida, 1964).

So, it might be safe to say that the similarities among human cultures and physical and mental activities lay bases for arousing similar response between source text readers and target text readers.

However, some people deny the possibility of arousing similar response in translation. They argue that different people may have different interpretations of the same message. This is correct to some degree, but we cannot deny that there is something in common in their interpretation. If there is no similarity in people's understanding of a certain message, no effective communication is possible even within the same speech community, let alone communication between different speech communities. Let's take a toy model plane for example. On the one hand, it does have different meaning to different people, for instance, to the producer, it may stand for "profit"; to a child, it is "a good toy"; and to a thrifty mother, it may imply "waste of money". They are really different. On the other hand, it surely means something that is shared by them all, that is, it is a "toy model plane". Similarly, although different people may have different impressions of Lin Daiyu (the heroin of Cao Xueqin's masterpiece A Dream of Red Mansions), they surely have some common impressions of her, such as "She is beautiful." "She is sentimental", etc. At least, few people might think that she is ugly.

Examples of "similar response" can also be found in actual life. When people see a moving film, most of them will be moved, some of them even to tears; and at least, no one laugh. On the contrary, when seeing humorous films, hearing or reading jokes, most people would be amused or laugh (so long as they get the point); at least no one feels sad in this situation. All these suggest that there does exist "similar response", which can be elicited in translation.

\section{CONCLUSION}

As is known to all, translation in essence is a kind of communication; therefore, the basic requirement of it should be to establish equivalence between the source text and the target text. However, as the basic requirement of translation, translation equivalence can never be identity but just a kind of approximation. Likewise, the response that a D-E translation strives for can only be "substantially the same" between the two groups of readers, but never identical. We know that any kind of intralingual communication is subject to a loss of message. In translation, which in fact is an interlingual and inter-cultural communication, the loss of message is naturally more. Because of this, some people deny the validity of the principle of dynamic equivalence. However, the fact that it is impossible to arouse absolutely identical response between the source language readers and the target language readers does not mean that the principle of dynamic equivalence is invalid. Professor Jin Di assimilates this to the case of seeking pure gold by saying that one hundred percent pure gold is just an ideal that no on has ever obtained so far; however, if we "give it up and do not refine it at all, perhaps it is impossible for us to get ninety-nine percent pure gold (Jin Di, 1988, p.40).

So, we can draw the conclusion that the principle of dynamic equivalence has both linguistic bases and cultural and psychological bases. The former enable the possibility of faithful reproduction of the original message, namely, the "closest natural equivalent of the source- language message" while the latter guarantee the possibility of "similar response." It is of validity and feasibility in practical translation.

\section{REFERENCES}

[1] Catford, J. C. (1965). A linguistic theory of translation. London: Oxford University Press.

[2] Gentzler, Edwin. (1993). Contemporary translation theories. London: Routledge.

[3] Jin Di. (1988). Approach to equivalent translation. Beijing: China Foreign Education Publishing Corporation.

[4] Jin Di \& Eugene A. Nida. (1984). On translation: with special reference to Chinese and English. Beijing: China Translation \& Publish Corporation, 1984.

[5] Liu Zhongde. (1991). Ten lectures on literary translation. Beijing: China Translation \& Publishing Corporation.

[6] Newmark, Peter. (1988). A text book of translation. Hemel Hempstead: Prentice Hall International Ltd. 
[7] Nida, Eugene A.. (1964). Toward a science of translating. Leiden: E. J. Brill.

[8] Nida, Eugene A. (1975). Language structure and translation. Stanford: Stanford University Press.

[9] Nida, Eugene A. (1993). Language, culture and translating. Shanghai: Shanghai Foreign Language Education Press.

[10] Nida, Eugene A. \& Charles R. Taber. (1982). The theory and practice of translation. Leiden: E. J. Brill.

[11] Nida, Eugene A. \& Jan de Waard. (1986). From one language to another: functional equivalence in bible translating. Nashville: Thomas Nelson Publishers.

[12] Snell-Hornby, Mary. (1988). Translation studies: an integrated approach. Philadelphia: John Benjamin's Publishing Company.

Yinhua Xiang was born in Chongqing, China in 1966. He received his M.A degree in translation from Sichuan International Studies University, China in 2000.

$\mathrm{He}$ is currently a lecturer in the School of Foreign Languages, Chongqing Jiaotong University, Chongqing, China. His research interests include theory and practice of translation, teaching theory and method of English and lexicology. 